\title{
Holism and Life Manifestations: Molecular and Space-Time Biology
}

\section{J. KŘEČEK ${ }^{1,2}$}

Formerly ${ }^{1}$ Department of the Physiology of Individual Development, Institute of Physiology, Academy of the Sciences of the Czech Republic, Prague, Czech Republic, ${ }^{2}$ Department of Clinical Pathology, Kuwait University, Kuwait

Received December 12, 2009

Accepted March 9, 2010

\section{Summary}

Appeals of philosophers to look for new concepts in sciences are being met with a weak response. Limited attention is paid to the relation between synthetic and analytic approach in solving problems of biology. An attempt is presented to open a discussion on a possible role of holism. The term "life manifestations" is used in accordance with phenomenology. Multicellular creatures maintain milieu intérieur to keep an aqueous milieu intracellulair in order to transform the energy of nutrients into the form utilizable for driving cellular life manifestations. Milieu intérieur enables to integrate this kind of manifestations into life manifestations of the whole multicellular creatures. The integration depends on a uniqueness and uniformity of the genome of cells, on their mutual recognition and adherence. The processes of ontogenetic development represent the natural mode of integration of cellular life manifestations. Functional systems of multicellular creatures are being established by organization of integrable cells using a wide range of developmental processes. Starting from the zygote division the new being displays all properties of a whole creature, although its life manifestations vary. Therefore, the whole organism is not only more than its parts, as supposed by holism, but also more than developmental stages of its life manifestations. Implicitly, the units of whole multicellular creature are rather molecular and developmental events than the cells per se. Holism, taking in mind the existence of molecular and space-time biology, could become a guide in looking for a new mode of the combination of analytical and synthetic reasoning in biology.

\section{Key words}

Photon • Homeostasis • Histocompatibility • Ontogenesis • Phenomenology • Ontology

\section{Corresponding author}

J. Křeček, Pražská 231, 25225 Jinočany, Czech Republic. E-mail: 257961277@iol.cz

The level which a science has reached is determined by how far it is capable of a crisis in its basic concepts... In biology there is an awakening tendency to inquire beyond the definitions which mechanism and vitalism have given for "life" and "organism", and to define anew the kind of Being which belongs to the living as such.

M. Heidegger, Sein und Zeit, 1927

Recently Linhartová (2003) published a biography of the professor of Charles University Jan Bělehrádek (1896 - 1980), which includes a chapter "Bělehrádek as a philosopher" written by Pavel Jerie. Bělehrádek was interested among others in holism, a branch of the philosophy of nature emphasizing the concept of living being as an indivisible whole. In his essay on holism Bělehrádek (1937) substantiated his belief that "the time is ripe for holism" and that "the new teaching comes as an inevitable answer to the ruling way of thinking, which is mainly atomistic and analytical". At the beginning of the 20th century another professor of Charles University, Edward Babák (1916), has already called for the reaction to mainly atomistic and analytical way of thinking.

Bělehrádek's treatise is based in particular on the work of Smuts (1927). Jan Christian Smuts, who is considered the father of the concept of "holism", was an extraordinary personality. He became famous for his 
participation in Boers war and conquest of German colonies in Africa during the First World War, he was cofounder of Royal Air Force, deserves merit for his activities in establishing the League of Nations after the First World War and the United Nations after the Second one. His publication furnishes a testimony of his extensive knowledge in the field of natural sciences. He was able to comment Einstein's theory of relativity as well as Darwin's theory of development. For him the cell was the second structure establishing universe; the atom being the first. Cell differs from atom by greater complexity, differentiation and specialization of its components so that the whole results from the cooperation between these components. He considered the evolution as an essential and generally recognized process of the creation of the world. He presumes, however, that this recognition did not result in reassessment of existing methods of exploration of the world. Dominance of the doctrine of causality persists while the broad field of uncertainty as a possible subject of investigation remains neglected. It would be therefore advisable to develop the concept of "fields", as a way of return to exploration of the fluent plasticity of nature. Matter, life and mind appear to be separated by barriers, but in reality they are common constituents of beings, such as man. The wholeness, according to Smuts, is a mode of totality of living beings, where the properties do not only cumulate, but in their mutual relations they acquire a new, special conformation and structure. The whole and its parts affect and determine each other. Such a synthesis of the whole and its parts is the object of interest for holism.

Holistic concept was further developed by Nikolai Hartmann (1940) with his hypothesis of the „emerging reality levels". According this hypothesis, categories of a lower quality become part of the categories of higher quality, but not vice versa. However, the higher categories affect the lower ones. Thus the level of life emerges from the category of matter, the level of mind from life and society from the category of mind. Work of Hartmann was opposed by the critical studies on the theory of the levels of reality presented by Roberto Poli (2001). The general theory of systems and resulting specific openness for living systems formulated by Ludwig von Bertalanffy (1951) is also largely based on a holistic concept. It stands here in opposition against reductionism, for which acquiring of properly obtained individual data is sufficient for understanding of the world. Of course, there is also an undeniable importance of the reductionistic approach consisting of development, improving and introducing adequate and efficient means of investigation. For a wider application of holistic principle, however, such resources are still only looked for, namely in the computer modeling of complex subsystems using computing techniques. According to Denise Noble (2006), however, today the task consists not in introducing new technical methods but in changing the way of thinking.

Holism seems to be a certain way of philosophizing. It may be therefore useful to mention here two branches of philosophy developed in the course of 20th century - Husserl's (1963) phenomenology and Heidegger's (1927) ontology. With phenomenology a character of the observer is introduced taking entities (phenomena) as they are perceived instead of taking them as they are. The perceiving observer forms an image of these phenomena in his mind and gives them a name. From the physiologist's perspective the task of the observer is to project into his mind and to treat there any information flowing from his system of senses. This might be the process of performing Husserl's „reduction of the whole experience to the pure consciousness", taking all what is given and accessible to mind as the "pure phenomenon". Interest shall be moved from contents of entities to mode of their presenting, from what to how. Two kinds of phenomena can be distinguished: one of beings (creatures) showing life manifestations, and one of objects not showing such mode of manifestation. Creating notions, as it will be shown in the following paragraphs, is driven by accessible form of energy of solar radiation becoming utilizable for this purpose by a series of processes modifying energy of photons. Transforming energy of photons is in addition involved in the function of cellular receptors of the retina of eyes, where it is raising neural impulses transmitted subsequently to the brain analyzers, where the visual percepts originate. Thus the energy of photons makes possible not only life manifestations but the perception of them by the observer as well. The term "life manifestations" that will frequently appear in this paper, was chosen with respect to these considerations.

In the middle of the $19^{\text {th }}$ century, many years earlier than Smuts, a French physiologist Claude Bernard (1878) considered the question related to the entirety of living beings. He concluded that instead of considering indivisibility of organism the attention should be oriented towards reasoning of organism as a whole being composed of a large number of units, each of them - 
specialized in various ways - is living in the milieu intérieur. Consequently, life of the entire organism is a result of activity of partial organs and their units. Cells (mentioned as units) take out from the milieu intérieur all they need for breathing and nourishment and release into this milieu products of their metabolism. A controversy between standpoints of representatives of holism and of Bernard is only superficial. Bernard simply pointed out the importance of constituents of the wholeness of multicellular organisms. In this way he proved a possible pathway to rational combination of analytical and synthetic endeavor for investigating in biological sciences. Even today it may be worth trying to take constituents of the wholeness into account in considering outcome of current discoveries, especially in molecular biology and developmental physiology. Some of them, as they appear namely in studies of mammals, can be found in more details in a treatise on the role of genes, environment and development in forming individuals (Křeček 2007).

According to contemporary knowledge, the milieu intérieur was identified as extracellular fluid whose properties are regulated in order to maintain optimal conditions for the life manifestations of cells. As already stated by Walter Bradford Cannon (1932), the osmotic pressure, volume and acidity of extracellular fluid are submitted to a regulation. This maintenance of steady properties of milieu intérieur was called homeostasis.

Molecules of water, which is a constituent component of extracellular fluid, are essential for life manifestations, because - as shown in the sixties of the past century - they take part in a chain of processes transforming energy of photons of sunlight into a form of energy that can be utilized for the accomplishment of these manifestations. Transformation starts at one of the three cell membranes of chloroplasts of green plants or at plasmatic membrane of photosynthetic algae. Water molecules, under the influence of the energy of photons, are reduced and apart from formation of molecular oxygen the utilizable form of energy is secured as highenergy bonds of adenosine triphosphate (ATP). This energy is used in plants for the synthesis of nutrients which are eventually used to drive life manifestations in animals. For this purpose the energy becomes available following its transitory storage in high-energy bonds of ATP that takes place in mitochondria. Mitochondria are specialized intracellular organelles which differ from other organelles by having two cell membranes instead of one. The external one separates the mitochondrial fluid from the gel-like cytosol of the intracellular milieu. A chain of enzymes anchored in the internal membrane is synthesized according to the genes of the mitochondrial own DNA (mtDNA). By oxidation of nutrients and with participation of these enzymes the electrons are loaded with energy. This form of energy is used to achieve asymmetric distribution of proton $\mathrm{H}^{+}$across the internal membrane making possible the formation of a gradient of electrochemical potential. Thus a temporary reserve of energy is created. As the energy of high-energetic electrons is depleted in the course of their transfer along the membrane, protons are returning to normal distribution. They enter into enzymatic system of ATP synthesis, where they are oxidized back into water molecules while the energy of electrochemical potential is transformed to energy of high-energy phosphate bonds of ATP. Energy is later released by hydrolysis of these bonds and used to drive molecular mechanisms of life manifestations. Protons used in this transformation of energy come from molecules of water due to different attractiveness of electrons toward nuclei of hydrogen and oxygen atoms causing the formation and extinction of ions $\mathrm{H}_{3} \mathrm{O}^{-}\left(\mathrm{H}_{2} \mathrm{O}+\mathrm{H}^{-}\right)$and $\mathrm{OH}^{-}\left(\mathrm{H}_{2} \mathrm{O}-\mathrm{H}^{+}\right)$in water.

$\mathrm{pH}$ which represents the concentration of $\mathrm{H}^{+}$in the fluid between external and internal membranes of mitochondria should be reduced due to one-way transport of protons across the internal membrane. In fact, it is kept at neutral level $\left(\mathrm{pH}\right.$ 7), when the concentrations of $\mathrm{H}_{3} \mathrm{O}^{+}$ and of $\mathrm{OH}^{-}$are equal. Under these conditions the demands of energy for setting up an asymmetric distribution of proton across the membrane are minimal. Intracellular milieu, however, is flooded with acid metabolites, e.g. carbonic acid produced by mitochondria, causing a tendency to lower $\mathrm{pH}$. Under these circumstances homeostasis of the milieu intérieur proves to be essential. Normally $\mathrm{pH}$ in the intracellular milieu will not fall below 7, due to the regulation of acid base equilibrium of extracellular fluid.

In order to utilize the processes of energy transformation in multicellular creatures, it is necessary to produce and maintain their own reserve of water molecules. For this purpose they withhold part of water and sodium ions out of the consumed water and food and set three compartments of body fluids: milieu intracellulair, intérieur and extérieur. Water and sodium are distributed between milieu intracellulair and intérieur by regulation of the osmotic pressure (osmoregulation) and the volume (volumoregulation) taking advantage of 
the renal functions, water drinking and sodium chloride intake. Changes of osmotic pressure, that are dependent mainly on the concentration of sodium ion $\left(\mathrm{Na}^{+}\right)$, are recorded by osmoreceptors of the brain regulatory center with resulting activation or suppression of thirst feeling and of neurohypophyseal secretion of antidiuretic hormone $(\mathrm{ADH})$ controlling urine excretion. Important for volumoregulation is a partition of total volume of extracellular fluid into intercellular and intravascular compartments separated by walls of blood capillaries. Changes in the volume of the intravascular compartment (i.e. blood volume) are registered by receptors located mostly in the right heart atrium and juxtaglomerular complex of the kidney. Both, the atrial natriuretic factor and renal renin participate in the regulation of the volume of fluid separated from the blood plasma by glomerular filtration and its reabsorption from the filtrate in the course of its flow through kidney tubules. Blood plasma as part of both milieu intérieur and circulating blood has an important homeostatic function because it is involved in the exchange of molecules contained in milieu extérieur, i.e. fluids covering the surface of pulmonary alveoli, mucous membrane of gastrointestinal tract and of excretory renal and sweat pathways. Respiratory gases are exchanged in pulmonary alveoli, nutrients in gastrointestinal tract, electrolytes and waste products of metabolism in kidneys and sweat glands.

In summary, multicellular creatures maintain homeostatic milieu intérieur in order to make up water reserve they require to keep an aqueous intracellular milieu necessary for transforming of energy of nutrients as a final phase of transformation of energy of sunlight photons into the form of energy utilizable for driving cellular life manifestations. Milieu intérieur then enables to integrate cellular life manifestations into life manifestations of their own multicellular creatures. However, the cells themselves must be integrable.

Integrable are those cells that originate from a fertilized ovum (zygote). They associate to form tissues by means of integrin molecules built in their plasmatic membrane and operating as receptors of recognizing molecules produced by the adjacent cells. John Bernard Gurdon (1962) demonstrated that all such cells contain in their nuclei a complete copy of genome of that zygote, from which they originate. Differences in life manifestations of integrable cells of different tissues are caused by different regulations of the same genome and not by different genomes. Genome of a zygote ensues from the fusion of haploid gametes (voluminous maternal ovum and minute paternal sperm), each taking only one out of two copies of deoxyribonucleic acid (DNA) from parental genome. For generations, such genes of assembled genomes were recombined by mutual exchange of sections of DNA and therefore there is only a minimal probability for the occurrence of the same combination. This uniqueness of genome is manifested by incompatibility of transplants in experiments with a transfer of tissue of one individual to the other. The immune relations between donor and recipient cells were established as the cause of this incompatibility. Their plasmatic membranes contain built-in molecules of the so-called histocompatibility antigens, the role of which is to inform the other cells, that they share a common cellular set of the same individual and that only their cellular life manifestations are integrable into life manifestations of that whole creature. The genes coding for human histocompatible antigens are at least 50 in number, but on a single chromosome there are placed maximally four of them. A spectrum of combinations emerges in this way and the probability that two individuals appear with the same set of histocompatible antigens is extremely low. Cells of two individuals are therefore as a rule mutually foreign and the donor's histocompatible antigens induce a defensive response of the recipient in the form of antibody production. The result is a refusal of transplant.

In summary, the assembling of cells into whole multicellular beings depends on a uniqueness and uniformity of genomes of integrating cells, on their mutual recognition as members of set of such unique cells and on their mutual adherence. The life manifestations of whole multicellular beings are then determined by the pattern of organizing life manifestations of integrable cells. The following paragraphs present an attempt to show that the natural mode of integration of cellular life manifestations into activities of organs and whole creatures is represented by processes that underlie the ontogenetic development of the individual from zygote.

Development of mammalian individuals begins with the fusion of gametes to establish a zygote. The share of sperm in the volume of the intracellular milieu of the zygote is negligible in comparison with share of ovum. Therefore a newborn animal inherited from its mother besides one half of the genome also her intracellular milieu and her mitochondria with their set of enzymes, necessary for production of the utilizable energy, which are synthesized in accordance with their own, on the cell nucleus independently inherited DNA. 
Mitochondria are able to reproduce themselves and in the course of each mitotic cell division they pass over into daughter cells as descendants of primary maternal mitochondria. Thus the long-lasting implementation of developmental programs of the zygote is carried out in vital dependence on providers of the necessary utilizable energy - mitochondria - of exclusively maternal origin.

After a zygote is assembled, the ability of cell division lost with the formation of gametes is restored and proliferation (multiplication) of integrable cells by mitotic divisions begins. It starts inside the zona pellucida - a mucous film covering the zygote - inherited from the mother as well. Zona pellucida precludes scattering of the first embryonic cells, but keeps them all squeezed inside a limited space to share the intracellular milieu of the zygote. Already at this step of development, cells produce their own milieu intérieur using membrane enzyme ATPase which retains potassium ions inside and pushes sodium ions outside the cell. By multiplying integrable cells surrounded by their own milieu intérieur the embryo is initiating its existence as a whole organism. Its life manifestations start to differentiate depending on the position that the single cells occupy: either inside the group or on its periphery, where they adhere to zona pellucida. From those located inside the epiblast a proper embryo will develop, whereas from the external trophectoderm it will arise that part which will nest the embryo in uterus and temporarily mediate its supply of nutrients and oxygen. Thus the exchange of substances with the mother is initiated. Due to synchronized transformation of cells of the uterine mucous membrane to decidual cells the mother becomes ready to establish a contact with the embryo. This is a critical period of development: if synchronization fails, the embryo will perish. Germ cells actively get rid of zona pellucida, trophectodermal cells are transformed to trophoblast, that penetrates aggressively into uterine decidua and secures a supply of the germ until placental exchange of nutrients and respiratory gases between maternal and embryonic blood takes over. Trophoblastic cells produce hormones, which are transported to maternal target cells by blood circulation. These hormones support the formation of the decidual cells, the maintenance and correct termination of pregnancy, the inhibition of maternal consumption of glucose in order to preserve it for the embryo, the conversion of the function of milk glands securing the future nourishment of the newborn. Mammalian individual keeps in this way the communication with its mother, and secures optimal conditions for its present and future existence already since the very early stages of its development.

Programs of development of the epiblastic cell genomes are launched by the translation of regulatory protein molecules leading to gene expression. In some cells of mouse epiblast, for instance, a gene called goosecoid ( $g s c$ ) was detected and from here the primitive streak begins to be shaped, one of the earliest embryonic structures. About 6 hours later, expression of the gsc becomes extinct and is replaced by the expression of a gene named brachyury (bra). It is supposed that the protein molecules arising from the expression of bra regulate the activity of genes coding adhesive protein molecules making thus possible the cell migration. The migrating cells penetrate into groups of cells with different properties and they can mutually interact. The discovery of homeotic gene complexes opened the path to elucidation of the mechanisms of space-time organizing cells into functional systems. Other gene system raises a translation of proteins participating in defining the boundaries between different developing structures. In later stages non-protein molecules are also used as regulators of developmental processes. For example, the secretion of androgenic steroidal hormones in proper time is crucial for the development of male phenotype. The delay in the onset of synthesis of these hormones causes the development of the female phenotype in males. Androgens take part first in the differentiation of cells forming gonadal pathways for sperms to give them the possibility to be ejaculated later into the female reproduction organs. Mammalian reproductive functions, however, continue to develop for a long time after birth and culminate with their maturation in puberty. Like for many other functional systems, hypothalamus is a regulatory center for reproductive functions. The decision whether its function will be of male or female type, comes already in fetal or neonatal stage of development. If hypothalamic functions would not be influenced by sexual steroid hormones in the course of these developmental stages, female type of hypothalamic functions would develop even in males. Timing of the period of sensitivity towards androgen effects is of critical importance - in laboratory rats it takes only a few days. The development of male reproductive functions is evidently dependent on the synchronization of translation of molecules of testicular enzymes synthesizing steroidal hormones and of receptor molecules responding to effect of these steroids in hypothalamus. Manifestations of the influence of steroids applied in the course of this critical 
period, however, become apparent in physiological reproductive functions much later than it took place. On the contrary, the development of female phenotype is independent of female steroidal or any other hormones.

Environment of mammals undergoes in some life stages, for instance at birth or in the course of weaning, natural and legitimate changes. Transformation in the neonatal period is radical. A newborn leaves the womb of its mother and as a suckling it is confronted with the challenge never met before. During the intrauterine stage of development it gets ready for meeting these new life conditions so favorably that it is able e.g. to sustain enormous load in expanding its lungs in order to perform the first inspiration of air. Less radical, but still dramatic change is represented by the gradual fading away of maternal care from its life environment during the weaning period. The preparation for a life without maternal nurture is culminating in this developmental stage, namely in the development of the gastrointestinal tract and in the regulation of water excretion by kidneys.

In the suckling period the laboratory rats have to share breast milk with their numerous siblings. If less numerous, they are overfed, when more numerous, they suffer from malnutrition. The rats undernourished in adulthood become slim but their body weight quickly settles if they are later supplied with food in sufficient quantity. In contrast, the rats undernourished in the course of suckling period are growing less for lifetime in comparison with their relatives overfed in this period, although both groups of animals have enough food since weaning. Faster growing rats achieve earlier sexual maturity. They are also more active in exploring foreign environment, take better care for their cleanness and their behavior is more emotive. Normally it takes 14 days until the rat young, after passing two weeks of suckling, begins the gradual process of weaning. Weanlings, however, survive, even if their mother is removed from the nest on the 15th -16 th day after birth. They will lose weight for a couple of days, but at the end of weaning, i.e. 30 days after birth, they will settle weight losses and since that time they grow like the normally weaned animals. However, as soon as they reach the age of approximately two years, they begin to increase their body weight so that their weight exceeds by up to $50 \%$ body weight of normally weaned relatives before they begin to lose weight due to ageing. Late manifestation of the effect of premature weaning is not limited to body weight changes. Influenced are also the resistance to infectious and noninfectious diseases as well as the fertility of both males and females. In early weaned rats it is also difficult to elaborate conditioned reflexes and they remember worse what they have learned. A failure of maternal behavior in prematurely weaned rat mothers appears to involve the inability to build regular nest for their offspring. Equally affected are their daughters, although they themselves were weaned normally and it seems that the same failure occurs even in the third generation.

Hence, functional systems of multicellular creatures mentioned by Bernard as organs are being established by organization of integrable cells using a wide range of developmental processes. This way of formation of functional systems has so far attracted less attention that it deserved. A branch of science dealing with this process has still not even its own name.

Knowledge collected for years elapsed since the Bernard's discovery of the milieu intérieur modified substantially the image of constituents of the wholeness of multicellular creatures. It turned up that the organization of cells - Bernard's „units" - into multicellular creatures is conditioned by their integrability based on the uniqueness of their genome, ability to mutual distinguishing and adhering. The existence of molecular mechanisms underlying cellular life manifestations, is dependent on usable form of energy arising from a series of processes transforming energy of photons and involving free protons provided by the dissociation of water molecules. The dissociation of cellular water molecules is kept in balance by regulation of $\mathrm{pH}$ of extracellular fluid through homeostatic mechanisms. Perhaps just that feature constitutes the main function of milieu intérieur. Formation of the organs - the third from Bernard's constituents of wholeness - happens by developmental processes starting from zygote division. These processes include not only the implementation of inborn programs of development, but also short- and long-term adaptations accompanied frequently by consequences emerging after long time elapsed. Starting from the first mitosis following a zygote division the new organism displays all properties of a whole creature, although its life manifestations vary in the course of development. This mode of wholeness takes over for a certain time and ends with the extinction of life manifestations. So the whole organism is not only more than its parts, but also more than its developmental stages of life manifestations. Implicitly, Bernard's units as elements of the whole multicellular creature are rather molecular and developmental events or incidents than cells. 
According to Smuts, wholeness is a mode of completeness of living creatures. As it was shown, it is also a mode of being of these creatures. It is the integration of elementary life manifestations that take some time in some gradually filled space. The being is the main topic of ontology. In order to relate being to an individual, Heidegger (1927) introduced an expression "Dasein", which is difficult to translate (perhaps "staying in the world through life manifestations"). For a physiologist it may denote being of a whole which displays life manifestations, in other words that the existence of a creature is limited by being of its life manifestations. Dasein of a creature is ended with the extinction of its own life manifestations. In this way Dasein of a creature turns into being of an object, a thing. Many life manifestations are not directly observable, but by technical means and measurement, one can obtain the information making possible to conclude that such life manifestations exist. These, to the direct observation hidden, life manifestations occupying a defined space for a defined time, are the fundamental constituents of the space-time wholeness of creatures. Just their extinction provides information on the termination of creature existence. Indeed, the existence should somehow begin. The first mitotic division of zygote with specific genome seems to be the natural beginning of a unique creature. This notion of onset, however, is disturbed by the function of mitochondria as it is perceived by an observer. Their own genetic apparatus is not formed by merging half the male with half the female genome. It is not renewed by fertilization of ovum with sperm and therefore is not subjected to recombination. Mitochondria become a part of the zygote because they come with the intracellular milieu of ovum. They are able to reproduce independently by a mode of division resembling the division of prokaryotes and they are transferred to daughter cells by mitotic and meiotic divisions as well. From one generations to the other they are transmitted by maternal ova. They are here perhaps since the times when microorganisms taking the advantage of photon energy and producing oxygen blended in with the bigger, maybe more able microorganisms and guided them to aerobic metabolism. They perish with the extinction of life manifestations of creatures for which they worked, but only after their "sisters" were transferred by ovum to the new zygote. Without the usable form of energy they produce, there would be neither the genome, nor the cells and nobody would speculate of the wholeness of beings.

Holism is an achievement of mind concerning limited importance of individual experience. Reasoning about holism, taking in mind the existence of molecular and space-time biology and separating the supply of energy from other life manifestations, could become a guide to the birth of the new step of synthetic approach in biology.

\section{References}

BABÁK E: On the need of synthesis in analytic trends in today's genetics (in Czech). Biol listy 5: 202-205, 1916.

BĚLEHRÁDEK J: Holismus (in Czech). Biol listy 22: 169-179, 1937.

BERNARD C: Leçons sur les phénomènes de la vie commons aux animaux et aux végéteaux. J. B. Ballière, Paris, 1878.

CANNON WB: The Wisdom of the Body. Norton, New York, 1932.

GURDON JB: The developmental capacity of nuclei taken from intestinal epithelium cells of feeding tadpoles. J Embryol Exp Morphol 10: 622-640, 1962.

HARTMANN N: Der Aufbau der realen Welt: Grundriß der Kategorienlehre. De Gruyter, Berlin, 1940.

HEIDEGGER M: Sein und Zeit, Neomarius Verlag, Tübingen, 1927.

HUSSERL E: Cartesianische Meditationen. Martinus Nijhoff, Hague, 1963.

KŘEČEK J: Individual: Gene, Environment, Development. (In Czech: Jedinec: gen, prostředí, vývoj.) Academia, Prague, 2007.

LINHARTOVÁ V: Jan Bèlehrádek and his Path to Freedom of Mind (in Czech). Galén, Prague, 2003.

NOBLE D: The Music of Life: Biology beyond the Genome. Oxford University Press, Oxford, 2006.

POLI R: The basic problem of the theory of levels of reality. Axyomathes 12: 261-283, 2001.

SMUTS JC: Holism and Evolution. Macmillan, London, 1927.

VON BERTALANFFY L: General system theory - a new approach to unity of science. Human Biol 23: 303-361, 1951. 